\title{
Schisandrin A suppresses lipopolysaccharide-induced inflammation and oxidative stress in RAW 264.7 macrophages by suppressing the NF-кB, MAPKs and PI3K/Akt pathways and activating Nrf2/HO-1 signaling
}

\author{
DA HYE KWON ${ }^{1,2^{*}}$, HEE-JAE CHA ${ }^{3 *}$, EUN OK CHOI ${ }^{1,2}$, SUN-HEE LEEM ${ }^{4}$, GI-YOUNG KIM ${ }^{5}$, \\ SUNG-KWON MOON $^{6}$, YOUNG-CHAE CHANG ${ }^{7}$, SEOK-JOONG YUN ${ }^{8}$, HYE JIN HWANG ${ }^{9}$, \\ BYUNG WOO KIM ${ }^{10}$, WUN-JAE KIM ${ }^{8}$ and YUNG HYUN CHOI ${ }^{1,2}$ \\ ${ }^{1}$ Department of Biochemistry, Dongeui University College of Korean Medicine, Busan 47227; ${ }^{2}$ Anti-Aging Research Center, \\ Dongeui University, Busan 47340; ${ }^{3}$ Department of Parasitology and Genetics, Kosin University College of Medicine, \\ Busan 49267; ${ }^{4}$ Department of Biological Science, College of Natural Sciences, Dong-A University, Busan 49315; \\ ${ }^{5}$ Laboratory of Immunobiology, Department of Marine Life Sciences, Jeju National University, Jeju 63243; \\ ${ }^{6}$ Department of Food and Nutrition, College of Biotechnology and Natural Resource, Chung-Ang University, \\ Anseong 17546; ${ }^{7}$ Research Institute of Biomedical Engineering and Department of Medicine, \\ Catholic University of Daegu School of Medicine, Daegu 42472; ${ }^{8}$ Personalized Tumor Engineering Research Center, \\ Department of Urology, Chungbuk National University College of Medicine, Cheongju 28644; ${ }^{9}$ Department of \\ Food and Nutrition, College of Nursing, Healthcare Sciences and Human Ecology; ${ }^{10}$ Department of Life Science \\ and Biotechnology, College of Engineering, Dongeui University, Busan 47340, Republic of Korea
}

Received May 2, 2017; Accepted October 19, 2017

DOI: $10.3892 /$ ijmm.2017.3209

\begin{abstract}
Schisandrin A is a bioactive lignan occurring in the fruits of plants of the Schisandra genus that have traditionally been used in Korea for treating various inflammatory diseases. Although the anti-inflammatory and antioxidant effects of lignan analogues similar to schisandrin A have been reported, the underlying molecular mechanisms have remained elusive. In the present study, schisandrin A significantly suppressed the lipopolysaccharide (LPS)-induced production of the key pro-inflammatory mediators nitric oxide (NO) and prostaglandin $\mathrm{E}_{2}$ by suppressing the expression of inducible NO synthase and cyclooxygenase- 2 at the mRNA and protein levels in RAW 264.7 macrophages. Furthermore,
\end{abstract}

Correspondence to: Dr Wun-Jae Kim, Department of Urology, Chungbuk National University College of Medicine, 776, 1 Sunhwan-ro, Cheongju 28644, Republic of Korea

E-mail:wjkim@chungbuk.ac.kr

Dr Yung Hyun Choi, Department of Biochemistry, Dongeui University College of Korean Medicine, 176 Yangjeong-ro, Busan 47227, Republic of Korea

E-mail: choiyh@deu.ac.kr

${ }^{*}$ Contributed equally

Key words: schisandrin A, macrophages, inflammation, oxidative stress schisandrin A was demonstrated to reduce the LPS-induced secretion of pro-inflammatory cytokines, including tumor necrosis factor- $\alpha$ and interleukin-1 $\beta$; this was accompanied by a simultaneous decrease in the respective mRNA and protein levels in the macrophages. In addition, the LPS- induced translocation of nuclear factor- $\kappa \mathrm{B}(\mathrm{NF}-\kappa \mathrm{B})$, as well as activation of mitogen-activated protein kinases (MAPKs) and phosphatidylinositol-3 kinase (PI3K)/Akt pathways were inhibited by schisandrin A. Furthermore, schisandrin A significantly diminished the LPS-stimulated accumulation of intracellular reactive oxygen species, and effectively enhanced the expression of NF erythroid 2-related factor 2 (Nrf2) and heme oxygenase-1 (HO-1). These results suggested that schisandrin A has a protective effect against LPS-induced inflammatory and oxidative responses in RAW 264.7 cells by inhibiting the $\mathrm{NF}-\kappa \mathrm{B}$, MAPK and PI3K/Akt pathways; these effects are mediated, at least in part, by the activation of the Nrf2/HO-1 pathway. Based on these results, it is concluded that schisandrin A may have therapeutic potential for treating inflammatory and oxidative disorders caused by over-activation of macrophages.

\section{Introduction}

Inflammation, a cause of various diseases, may be accompanied by oxidative damage, and the synergistic effect of these conditions may increase with the worsening of numerous diseases. Lipopolysaccharide (LPS), a pathogenic endotoxin present in the outer membrane of gram-negative bacteria, promotes the inflammatory reaction and oxidative stress, 
and is commonly used to generate models of disease for evaluating the pharmacodynamic efficacy of drugs $(1,2)$. In particular, macrophages are activated when exposed to inflammatory stimuli such as LPS, resulting in excessive production of pro-inflammatory mediators and cytokines as well as reactive oxygen species (ROS) (3-5). Nitric oxide $(\mathrm{NO})$ and prostaglandin $\mathrm{E}_{2}\left(\mathrm{PGE}_{2}\right)$ are representative pro-inflammatory mediators. NO regulated by inducible NO synthase (iNOS) reacts with peroxides to promote oxidative stress and inflammatory processes $(6,7)$. $\mathrm{PGE}_{2}$, another important mediator synthesized from arachidonic acid metabolites, is catalyzed by cyclooxygenase-2 (COX-2) during the inflammatory response $(6,8,9)$. In addition, major pro-inflammatory cytokines, such as tumor necrosis factor- $\alpha$ (TNF- $\alpha)$ and interleukin-1 $\beta$ (IL-1 $\beta$ ), are overexpressed in macrophages stimulated by LPS and contribute to the pathogenesis of various inflammatory diseases $(10,11)$. Accumulating evidence suggests that LPS causes overproduction of pro-inflammatory mediators and cytokines through the activation of nuclear factor- $\kappa \mathrm{B}(\mathrm{NF}-\kappa \mathrm{B})$ associated with the mitogen-activated protein kinases (MAPKs) and phosphatidylinositol-3 kinase (PI3K)/Akt pathways (12-14). In addition, inflammatory stress is known to increase reactive oxygen species (ROS) production and reduce the production of antioxidant enzymes that protect tissues from oxidative damage $(15,16)$. In particular, the induction of phase II detoxifying enzymes and cytoprotective genes, such as heme oxygenase-1 (HO-1), is mediated by NF-erythroid 2-related factor 2 (Nrf2), which has a central role in protecting cells against inflammation and oxidative damage (16-18).

The fruit of Schisandra chinensis (Turcz.) Baill. and Schisandra sphenanthera Rehd. et Wils. have been widely used for treating several diseases in Asia for thousands of years $(19,20)$. Numerous studies have attempted to identify the key phytochemicals present in these two fruits; to date, several lignan compounds have been identified as the major bioactive components $(21,22)$. Among them, schisandrin A, a dibenzocyclooctadiene derivative, has been indicated to have a role in the inhibition of inflammation and elimination of free radicals. For instance, the schisandrin A-enriched extract of Schisandra sphenanthera fruit has been reported to exert anti-inflammatory effects by inhibiting $\mathrm{PGE}_{2}$ production and suppressing COX-2 expression in $\mathrm{HaCaT}$ keratinocytes irradiated with ultraviolet B light (23). Schisandrin A also demonstrated a protective effect on primary cortical neurons against L-glutamate-induced neurotoxicity (24). Furthermore, by reducing the intracellular calcium concentration and causing the release of lactate dehydrogenase, it significantly improved the viability of primary cortical cells in the oxygen-glucose deficiency/reoxygenation model (25). In addition, schisandrin $\mathrm{A}$ has proven beneficial in preventing cell damage in the pathogenesis of central nervous system diseases, including ischemia, and regulated inflammation- and apoptosis-associated proteins in SH-SY5Y cells following glucose deprivation injury (26). Schisandrin A has also been reported to inhibit inflammation-induced neuronal damage by decreasing the production of NO, TNF- $\alpha$ and IL- 6 induced by LPS in microglial cells; furthermore, various signaling pathways, including the $\mathrm{NF}-\kappa \mathrm{B}$ pathway, were indicated to be involved in this process, suggesting that schisandrin $\mathrm{A}$ is a promising candidate for treating inflammatory neurodegenerative diseases (27). Similarly, this compound exhibited anti-inflammatory activity in LPS-stimulated RAW 264.7 cells; in particular, it increased glutathione S-transferase activity and decreased glutathione levels, thereby suppressing edema; this indicates that the anti-inflammatory action of schisandrin A is closely associated with its antioxidant effect (28). Furthermore, several previous studies have reported that lignan-like substances with a structure similar to that of schisandrin A possess anti-inflammatory activities and excellent Nrf2-induction or ROS-scavenging abilities (29-34); however, the underlying mechanisms associated with the antiinflammatory and antioxidant activity of schisandrin A have remained to be fully elucidated. Therefore, the present study evaluated the protective effect of schisandrin A and the underlying mechanisms associated with inflammation and oxidative stress in RAW 264.7 macrophages exposed to LPS derived from Escherichia coli (E. coli).

\section{Materials and methods}

Cell culture and LPS stimulation. The RAW 264.7 murine macrophage cell line was obtained from the Korea Cell Line Bank (Seoul, Korea) and maintained in Dulbecco's modified Eagle's medium (DMEM) containing 10\% (v/v) fetal bovine serum, L-glutamine $(2 \mathrm{mM})$, penicillin $(100 \mathrm{U} / \mathrm{ml})$ and streptomycin $(100 \mathrm{U} / \mathrm{ml})$ (all from WelGENE Inc., Daegu, Korea) at $37^{\circ} \mathrm{C}$ in a humidified atmosphere containing $5 \% \mathrm{CO}_{2}$ and 95\% air. Schisandrin A was purchased from Sigma-Aldrich (cat. no. SML0054; Merck KGaA, Darmstadt, Germany), dissolved in dimethyl sulfoxide (DMSO; Sigma-Aldrich; Merck KGaA) and final concentrations were adjusted by dilution with complete culture medium. The DMSO concentration did not exceed $0.05 \%$ (i.e., a non-cytotoxic range). To stimulate the cells, the medium was replaced with fresh DMEM, and LPS (E. coli Serotype 055:B5; cat. no. L2880; Sigma-Aldrich; Merck $\mathrm{KGaA}$ ) was added in the presence or absence of schisandrin A for the indicated periods.

Assessment of cell viability. To evaluate the cytotoxicity of schisandrin A, RAW 264.7 cells were seeded in 96-well plates at a density of $1 \times 10^{3}$ cells/well. The cells were treated with various concentrations of schisandrin A for $1 \mathrm{~h}$ prior to incubation with LPS $(100 \mathrm{ng} / \mathrm{ml})$ for $24 \mathrm{~h}$. After the incubation was complete, images of cells from each well were captured under a phase-contrast microscope (Carl Zeiss, Oberkochen, Germany). Subsequently, MTT (Sigma-Aldrich; Merck KGaA) was added to each well at $0.5 \mathrm{mg} / \mathrm{ml}$, followed by incubation at $37^{\circ} \mathrm{C}$ in the dark. After $3 \mathrm{~h}$ of incubation, the MTT solution was removed and $200 \mu 15 \%$ DMSO was added to dissolve the crystals. The viable cells were detected by reading the absorbance of formazan at $540 \mathrm{~nm}$ using an enzyme-linked immunosorbent assay (ELISA) microplate reader (Dynatech Laboratories, Chantilly, VA, USA). The optical density of the formazan formed in the control (untreated) cells was considered to represent $100 \%$ viability.

Measurement of $\mathrm{NO}$ and $P G E_{2}$ production. RAW 264.7 cells were pretreated with schisandrin A for $1 \mathrm{~h}$; subsequently, they were stimulated with LPS for $24 \mathrm{~h}$. Controls were maintained 
under the same culture conditions; however, they were not pre-incubated or stimulated. NO levels were indirectly determined by measuring the stable NO catabolite nitrite in the medium utilising the Griess reaction. In brief, the conditioned medium $(100 \mu \mathrm{l})$ was mixed with the same volume of Griess reagent (Sigma-Aldrich; Merck KGaA) and incubated for $10 \mathrm{~min}$ at room temperature. The optical density at $540 \mathrm{~nm}$ was measured using an ELISA microplate reader and the nitrite concentration was calculated according to a standard curve generated from known concentrations of sodium nitrite. The $\mathrm{PGE}_{2}$ concentration in the conditioned medium was measured using a commercial $\mathrm{PGE}_{2}$ ELISA kit (cat. no. 514010; Cayman Chemical Co., Ann Arbor, MI, USA) according to the manufacturer's instructions.

ELISA for pro-inflammatory cytokines. The generation of proinflammatory cytokines TNF- $\alpha$ and IL- $6 \beta$ was measured using ELISA kits. The RAW 264.7 cells were pre-incubated with schisandrin A for $1 \mathrm{~h}$, followed by LPS stimulation for $24 \mathrm{~h}$, and cytokine contents in the cell-free supernatants were measured using cytokine sandwich ELISA kits (cat. nos. MTA00B and MLB00C; R\&D Systems, Minneapolis, MN, USA) according to the manufacturer's protocols.

Reverse transcription-polymerase chain reaction (RT-PCR) assay. The RAW 264.7 cells were pretreated with various concentrations of schisandrin A for $1 \mathrm{~h}$, followed by treatment with LPS (100 $\mathrm{ng} / \mathrm{ml})$ for $24 \mathrm{~h}$. Controls were maintained under the same culture conditions, but were not pre-incubated or stimulated. Total RNA was extracted using TRIzol reagent (Invitrogen; Thermo Fisher Scientific, Inc., Waltham, MA, USA), according to the manufacturer's instructions. The complementary (c)DNA of each sample was prepared using $2 \mu \mathrm{g}$ RNA, $1 \mu 1$ Moloney's murine leukemiavirus reverse transcriptase, $1 \mathrm{mM}$ deoxynucleoside triphosphate and $1 \mu \mathrm{l}$ oligo(dT) according to the manufacturer's standardized protocol. DNA amplification was performed in AccuPower ${ }^{\circledR}$ PCR PreMix (Bioneer Corp., Daejeon, Korea). iNOS, COX-2, TNF- $\alpha$ and IL-1 $\beta$ genes were amplified from the cDNA using PCR (Eppendorf, Hamburg, Germany). After amplification, the PCR products were electrophoresed on $1 \%$ agarose gels and visualized following staining with ethidium bromide (Sigma-Aldrich; Merck KGaA) for 10 min at room temperature under ultraviolet irradiation using the Gel Documentation System (CHEMISMART 2026M.WL; Vilber Lourmat, Marne-la-Valle, France). Glyceraldehyde 3-phosphate dehydrogenase (GAPDH) was used as a loading control. The PCR primers were as follows: iNOS forward, 5'-ATG TCC GAA GCA AAC ATCAC-3' and reverse, 5'-TAA TGT CCA GGA AGT AGG TG-3'; COX-2 forward, 5'-CAG CAA ATC CTT GCT GTT CC-3' and reverse, 5'-TGG GCA AAG AAT GCA AAC ATC-3'; TNF- $\alpha$ forward, 5'-TCT CAT CAG TTC TAT GGC CC-3' and reverse, 5'-GGG AGT AGA CAA GGT ACA AC-3'; IL-1 $\beta$ forward, 5'-GGG CTG CTT CCA AAC CTT TG-3' and reverse, 5'-GCT TGG GAT CCA CAC TCT CC-3' and GAPDH forward, 5'-AGG CCG GTG CTG AGT ATG TC-3' and reverse, 5'-TGC CTG CTT CAC CAC CTT CT-3' (Bioneer Corp.). The PCR reaction was initiated at $94^{\circ} \mathrm{C}$ for $2 \mathrm{~min}$, followed by 25 cycles of $94^{\circ} \mathrm{C}$ for $30 \mathrm{sec}$, annealing temperature for $30 \mathrm{sec}$ and $72^{\circ} \mathrm{C}$ for $30 \mathrm{sec}$, and a final extension step at $72^{\circ} \mathrm{C}$ for $5 \mathrm{~min}$. The annealing temperatures were $63^{\circ} \mathrm{C}$ for iNOS, COX-2, TNF- $\alpha$ and IL- $1 \beta$, and $61^{\circ} \mathrm{C}$ for GAPDH.

Protein isolation and western blot analysis. The RAW 264.7 cells were incubated with schisandrin A at the indicated concentrations for $1 \mathrm{~h}$ prior to stimulation with LPS $(100 \mathrm{ng} / \mathrm{ml})$ for $24 \mathrm{~h}$. As described previously (35), the cells were collected, lysed with a cell lysis buffer and the protein concentration was determined using the Bradford Protein assay kit (Bio-Rad Laboratories, Hercules, CA, USA). In a parallel experiment, cytoplasmic and nuclear extracts were prepared using an NE-PER Nuclear and Cytoplasmic Extraction reagents kit (Pierce; Thermo Fisher Scientific, Inc.) following the manufacturer's instructions. For western blotting, equal amounts of protein samples (30 $\mu \mathrm{g} / \mathrm{lane})$ were subjected to $10-13 \%$ sodium dodecyl sulfate-polyacrylamide gel electrophoresis (SDS-PAGE) and then electrophoretically transferred onto polyvinylidene difluoride membranes (Schleicher \& Schuell, Keene, NH, USA). Subsequently, the membranes were blocked with 5\% non-fat dry milk in Trisbuffered saline containing $0.1 \%$ Triton X-100 (TBST) for $1 \mathrm{~h}$ and probed with specific primary antibodies (Table I) at $4^{\circ} \mathrm{C}$ overnight. After washing with TBST, the membranes were incubated with the appropriate horseradish peroxidase (HRP)-conjugated secondary antibodies (dilution, 1:500; cat. no. sc-2004, goat anti-rabbit IgG-HRP; sc-2005, goat anti-mouse IgG-HRP; Santa Cruz Biotechnology, Inc., Santa Cruz, CA, USA) for $2 \mathrm{~h}$ at room temperature. The protein bands were detected to X-ray film using an enhanced chemiluminescence kit (cat. no. RPN 2232; GE Healthcare Life Sciences, Little Chalfont, UK) according to the manufacturer's instructions.

Immunofluorescence staining for $N F-\kappa B$ nuclear translocation. The effect of schisandrin A on LPS-induced nuclear translocation of NF- $\mathrm{KB}$ was also assessed using immunofluorescence microscopy. The RAW 264.7 cells were first grown on glass coverslips for $24 \mathrm{~h}$ at $37^{\circ} \mathrm{C}$ in a humidified atmosphere containing $5 \% \mathrm{CO}_{2}$ and subsequently incubated with $200 \mu \mathrm{M}$ schisandrin A for $1 \mathrm{~h}$ prior to treatment with $100 \mathrm{ng} / \mathrm{ml}$ LPS for $30 \mathrm{~min}$ in the same culture conditions. The cells were fixed in $3.7 \%$ paraformaldehyde for $15 \mathrm{~min}$, permeabilized with $0.2 \%$ Triton X-100 in phosphate-buffered saline (PBS) for $15 \mathrm{~min}$ and blocked for $10 \mathrm{~min}$ at room temperature with PBS containing 5\% bovine serum albumin (Sigma-Aldrich; Merck KGaA). The cells were then stained with the primary antibody against NF- $\mathrm{kB}$ p65 (dilution, 1:100) overnight at $4^{\circ} \mathrm{C}$. Subsequently, cells were incubated with a fluorescein-conjugated anti-rat immunoglobulin G (dilution, 1:100; cat. no. 31629; Molecular Probes; Thermo Fisher Scientific, Inc.) in the dark for $40 \mathrm{~min}$ at $37^{\circ} \mathrm{C}$. Nuclei were sequentially stained with DAPI solution (2.5 $\mu \mathrm{g} / \mathrm{ml}$; Sigma-Aldrich; Merck KGaA). The slides were then mounted and fluorescence images were captured using a fluorescence microscope (Carl Zeiss).

Determination of intracellular ROS. The intracellular ROS production was monitored using 5,6-carboxy-2'7'-dichlorofluorescin diacetate (DCF-DA), as previously described (36). This substrate freely permeates the cells, and upon incorporation, it is oxidized to fluorescent DCF. In brief, RAW 264.7 cells were pretreated with $200 \mu \mathrm{M}$ schisandrin A for $1 \mathrm{~h}$ and then stimulated with or without $100 \mathrm{ng} / \mathrm{ml}$ LPS. After $6 \mathrm{~h}$ incubation, the 
Table I. List of antibodies used in the present study.

\begin{tabular}{|c|c|c|c|c|}
\hline Antibody & Dilution & Cat. no. & Species of origin & Supplier \\
\hline iNOS & $1: 1,000$ & BD-610328 & Rabbit polyclonal & BD Biosciences \\
\hline COX-2 & $1: 500$ & 160126 & Rabbit polyclonal & Cayman Chemical \\
\hline IL-1 $\beta$ & $1: 1,000$ & sc-7884 & Rabbit polyclonal & Santa Cruz Biotechnology, Inc. \\
\hline $\mathrm{TNF}-\alpha$ & $1: 1,000$ & $3707 \mathrm{~S}$ & Rabbit polyclonal & Cell Signaling Technology, Inc. \\
\hline NF-кB p65 & $1: 1,000$ & sc-109 & Rabbit polyclonal & Santa Cruz Biotechnology, Inc. \\
\hline I $\kappa \mathrm{B}-\alpha$ & $1: 1,000$ & sc-371 & Rabbit polyclonal & Santa Cruz Biotechnology, Inc. \\
\hline Lamin B & $1: 1,000$ & sc-6216 & Goat polyclonal & Santa Cruz Biotechnology, Inc. \\
\hline JNK & $1: 1,000$ & $9252 \mathrm{~S}$ & Rabbit polyclonal & Cell Signaling Technology, Inc. \\
\hline p-JNK & $1: 1,000$ & 9255 & Mouse monoclonal & Cell Signaling Technology, Inc. \\
\hline ERK & $1: 1,000$ & sc-154 & Rabbit polyclonal & Santa Cruz Biotechnology, Inc. \\
\hline p-ERK & $1: 1,000$ & $9106 \mathrm{~S}$ & Mouse monoclonal & Cell Signaling Technology, Inc. \\
\hline p38 MAPK & $1: 1,000$ & sc-728 & Rabbit polyclonal & Santa Cruz Biotechnology, Inc. \\
\hline p-p38 MAPK & $1: 1,000$ & 9211S & Rabbit polyclonal & Cell Signaling Technology, Inc. \\
\hline PI3K & $1: 1,000$ & 4257 & Rabbit polyclonal & Cell Signaling Technology, Inc. \\
\hline p-PI3K & $1: 1,000$ & 4228 & Rabbit polyclonal & Cell Signaling Technology, Inc. \\
\hline Akt & $1: 1,000$ & sc-8312 & Rabbit polyclonal & Santa Cruz Biotechnology, Inc. \\
\hline $\mathrm{p}-\mathrm{Akt}$ & $1: 1,000$ & sc-101629 & Rabbit polyclonal & Santa Cruz Biotechnology, Inc. \\
\hline Nrf2 & $1: 1,000$ & sc-13032 & Rabbit polyclonal & Santa Cruz Biotechnology, Inc. \\
\hline $\mathrm{p}-\mathrm{Nrf} 2$ & $1: 2,000$ & Ab76026 & Rabbit polyclonal & Abcam, Inc. \\
\hline HO-1 & $1: 1,000$ & 374090 & Rabbit polyclonal & Calbiochem, Inc. \\
\hline Keap1 & $1: 1,000$ & sc-15246 & Goat polyclonal & Santa Cruz Biotechnology, Inc. \\
\hline Actin & $1: 1,000$ & sc-1615 & Goat polyclonal & Santa Cruz Biotechnology, Inc. \\
\hline
\end{tabular}

iNOS, inducible nitric oxide synthase; COX, cyclooxygenase; IL, interleukin; TNF, tumor necrosis factor; NF- $\mathrm{BB}$ p65, 65-kDa subunit of

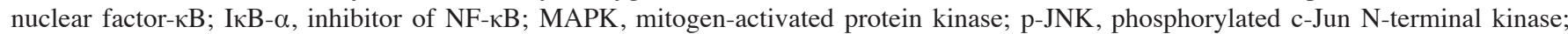
ERK, extracellular signal-regulated kinase; PI3K, phosphoinositide-3 kinase; Nrf2, nuclear factor erythroid 2-related factor 2; HO-1, heme oxygenase-1; Keap1; Kelch-like ECH-associated protein 1. Cell Signaling Technology, Inc., Danvers, MA, USA; Abcam, Inc., Cambridge, MA, USA; Calbiochem, Inc., San Diego, CA, USA.

cells were stained with $10 \mu \mathrm{M}$ DCF-DA (Molecular Probes; Thermo Fisher Scientific, Inc.) for $30 \mathrm{~min}$ at $37^{\circ} \mathrm{C}$ in the dark. The cells were collected, washed with PBS twice, and a total of 10,000 events were then immediately analyzed using a flow cytometer (BD Biosciences, San Jose, CA, USA). To confirm the involvement of elevated ROS in the LPS-induced inflammatory response, the cells were pre-incubated with $\mathrm{N}$-acetyl cysteine (NAC; Sigma-Aldrich; Merck KGaA), an established antioxidant, for $1 \mathrm{~h}$ prior to LPS treatment.

Statistical analysis. Each experiment was performed in triplicate and values are expressed as the mean \pm standard deviation. Statistical analysis was performed using GraphPad Prism software (version 5.03; GraphPad Software, Inc., La Jolla, CA, USA). Differences between groups were assessed using analysis of variance followed by Tukey's post hoc test or by the unpaired Student's t-test. $\mathrm{P}<0.05$ was considered to indicate a statistically significant difference.

\section{Results}

Effect of schisandrin A on the viability of RAW 264.7 macrophages. The RAW 264.7 cells were treated with different concentrations of schisandrin A for $1 \mathrm{~h}$ prior to incubation with $100 \mathrm{ng} / \mathrm{ml}$ LPS. An MTT assay was performed to select the concentration range of schisandrin A that would not affect the cell viability. Fig. 1A demonstrates that schisandrin A at up to $300 \mu \mathrm{M}$ in the presence, as well as in the absence of LPS did not affect the viability of RAW 264.7 cells. In addition, morphological changes in the RAW 264.7 cells treated with LPS alone were slightly alleviated by pretreatment with schisandrin A (Fig. 1B). Accordingly, the anti-inflammatory effects of schisandrin A at concentrations of $<200 \mu \mathrm{M}$ on RAW 264.7 macrophages were assessed.

Effects of schisandrin A on LPS-induced production of proinflammatory mediators in RAW 264.7 macrophages. To examine the effects of schisandrin A on the LPS-induced production of representative pro-inflammatory mediators $\mathrm{NO}$ and $\mathrm{PGE}_{2}$ in RAW 264.7 cells, the cells were pretreated with various concentrations of schisandrin A (50, 100 and $200 \mu \mathrm{M}$ ) for $1 \mathrm{~h}$. Thereafter, they were stimulated for $24 \mathrm{~h}$ with $100 \mathrm{ng} / \mathrm{ml}$ LPS. The NO and $\mathrm{PGE}_{2}$ levels in the cellular supernatants were assessed using Griess reagent and ELISA, respectively. Fig. 1 indicate that the stimulation of RAW 264.7 cells with LPS alone significantly increased the $\mathrm{NO}$ and $\mathrm{PGE}_{2}$ concentrations in the culture medium; which was reduced by schisandrin A in a dose-dependent manner. Therefore, it was 

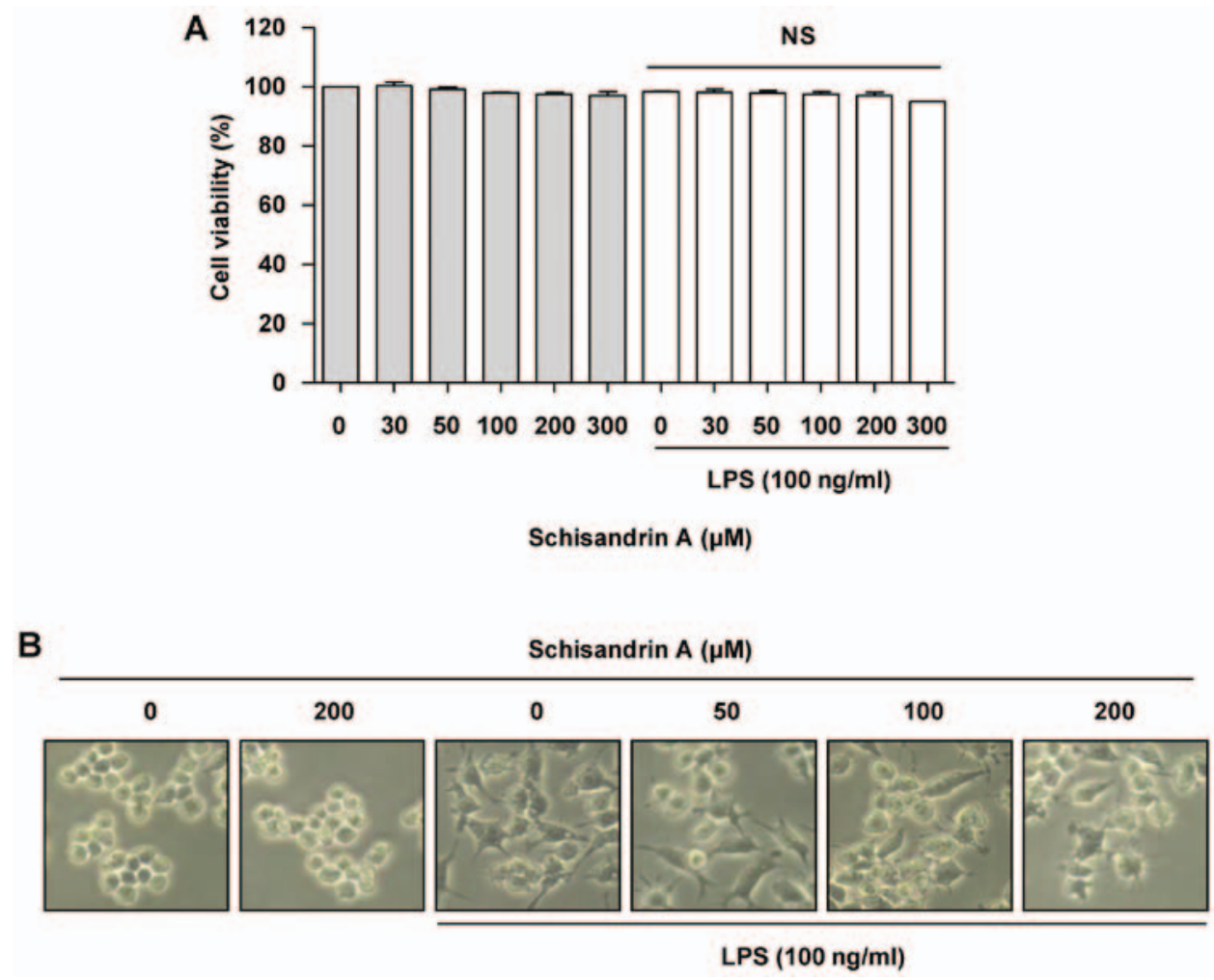

Figure 1. Effect of schisandrin A on the cell viability of RAW 264.7 macrophages. The cells were treated with the indicated concentrations of schisandrin A for $1 \mathrm{~h}$ prior to treatment with LPS (100 $\mathrm{ng} / \mathrm{ml}$ ) for $24 \mathrm{~h}$. (A) The cell viability was assessed using an MTT reduction assay and the results are expressed as the percentage of surviving cells compared with that in the control group (no addition of schisandrin A and LPS). Values are expressed as the mean \pm standard deviation of the three independent experiments. (B) Cell morphological changes were monitored by inverted phase-contrast microscopy. Representative photomicrographs of the morphological changes are presented (magnification, x200). NS, no significance; LPS, lipopolysaccharide.

investigated whether the inhibitory effects of schisandrin A on $\mathrm{NO}$ and $\mathrm{PGE}_{2}$ production were associated with the regulation of their synthesizing enzymes, iNOS and COX-2, respectively. It was revealed that iNOS as well as COX-2 mRNA and protein expression levels were markedly elevated in the LPS-stimulated RAW 264.7 cells. However, schisandrin A significantly reduced the LPS-induced expression of iNOS as well as COX-2 mRNA and protein in a concentration-dependent manner (Fig. 2C-F). These results suggest that schisandrin A inhibits $\mathrm{NO}$ and $\mathrm{PGE}_{2}$ production via downregulation of iNOS as well as COX-2 mRNA and protein levels.

Effects of schisandrin A on LPS-induced production of proinflammatory cytokines in RAW 264.7 macrophages. With the production of pro-inflammatory mediators, pro-inflammatory cytokines also have a crucial role in initiating the inflammatory response $(10,11)$. Therefore, it was assessed whether schisandrin A inhibits the production of pro-inflammatory cytokines, including TNF- $\alpha$ and IL-1 $\beta$, in LPS-treated RAW 264.7 cells. The results indicate that pretreatment with schisandrin A prior to the LPS challenge significantly reduced the TNF- $\alpha$ concentration in the culture medium of RAW 264.7 cells in a concentration-dependent manner. Furthermore, this was associated with the downregulation of its mRNA and protein expression. Similarly, schisandrin A effectively inhibited LPS-induced IL-1 $\beta$ secretion, as well as mRNA and protein expression (Fig. 3). These results suggest that schisandrin A also modulates inflammatory cytokine expression at the transcriptional level.
Schisandrin A inhibits LPS-induced nuclear translocation of $N F-\kappa B$ and degradation of $I \kappa B-\alpha$ in RAW 264.7 macrophages. The nuclear translocation of transcription factor NF- $\mathrm{KB}$ is considered a prerequisite for the transcription of genes associated with inflammatory processes $(12,13)$; therefore, the ability of schisandrin A to inhibit NF- $\mathrm{kB}$ translocation was investigated. Fig. 4 indicates that LPS stimulation markedly promoted the nuclear translocation of NF- $\mathrm{kB}$ p65 with a concurrent downregulation of I $\kappa \mathrm{B}-\alpha$. However, schisandrin A pretreatment markedly inhibited the translocation of $\mathrm{NF}-\kappa \mathrm{B}$ to the nucleus and restored the depleted IкB- $\alpha$ in the LPS-stimulated cells. In addition, LPS enhanced the nuclear accumulation of NF- $\mathrm{KB}$ p65, as evidenced by immunofluorescence staining; however, this was effectively reduced by schisandrin A pretreatment. These observations suggest that schisandrin A acts as a negative regulator of LPS-stimulated NF- $\kappa B$ activation in RAW 264.7 macrophages.

Inhibition of LPS-induced activation of MAPK and PI3K/Akt pathways by schisandrin A in RAW 264.7 macrophages. Previous studies have established that the MAPKs and PI3K/Akt signaling pathways are involved in LPS-induced inflammation in macrophages $(13,14)$. Therefore, the possible involvement of these signaling pathways in schisandrin A-mediated inhibition of LPS-induced inflammatory responses was examined in the present study. The immunoblotting results indicated that LPS treatment substantially promoted the phosphorylation of three MAPKs, c-Jun N-terminal kinase (JNK), p38 MAPK and extracellular signal-regulated kinase (ERK), as well as PI3K 
A
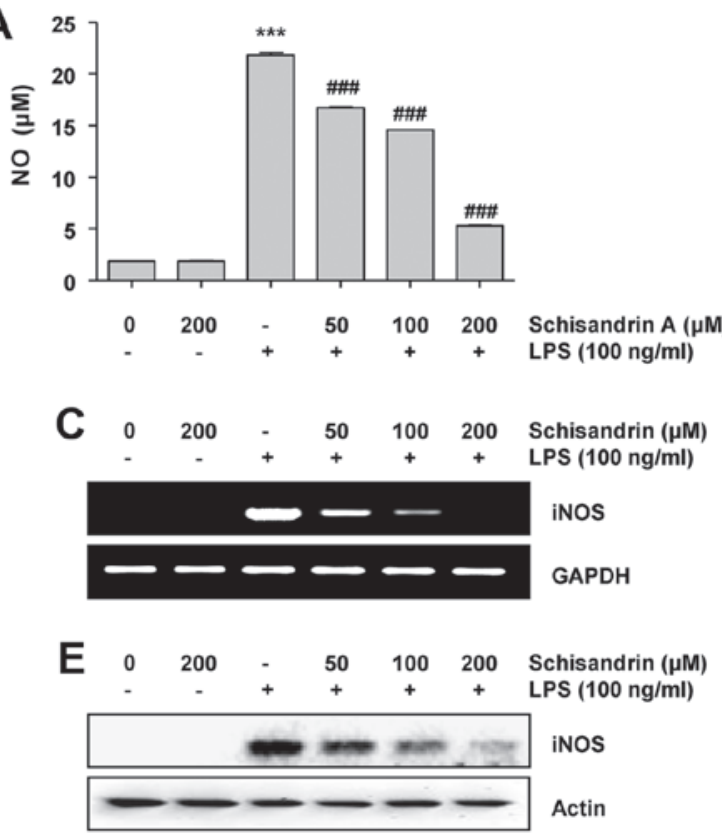
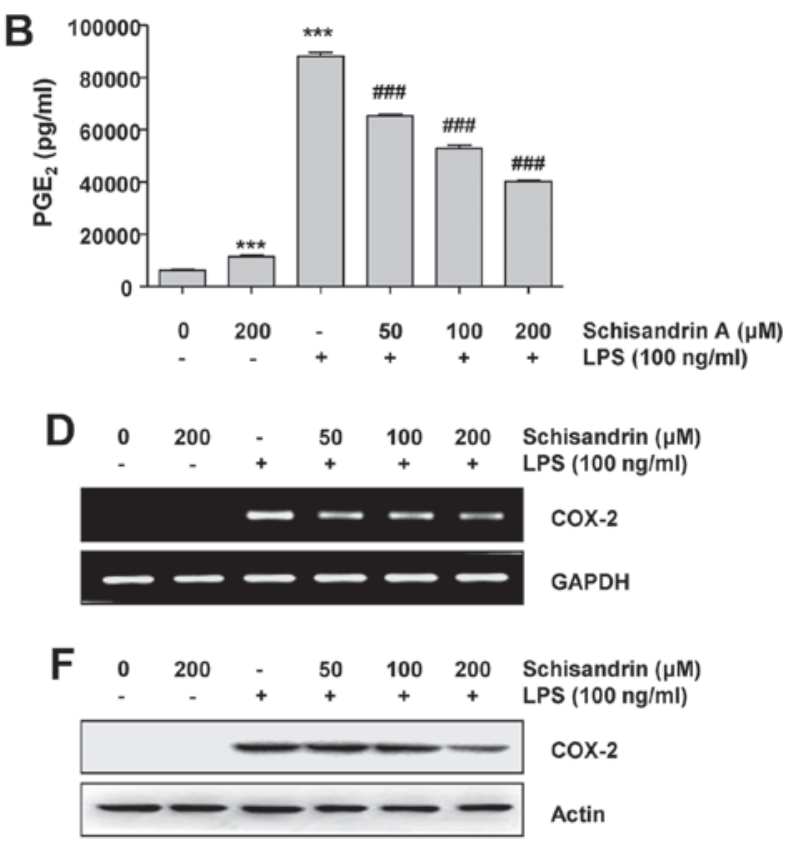

Figure 2. Inhibition of $\mathrm{NO}$ and $\mathrm{PGE}_{2}$ production by schisandrin A in LPS-stimulated RAW 264.7 macrophages. (A and B) RAW 264.7 cells were incubated for $1 \mathrm{~h}$ with the indicated concentrations of schisandrin A prior to stimulation with $100 \mathrm{ng} / \mathrm{ml} \mathrm{LPS} \mathrm{for} 24 \mathrm{~h}$. The amounts of (A) NO and (B) PGE 2 in the culture supernatants were determined via the Griess reaction and a commercial ELISA kit, respectively. Values are expressed as the mean \pm standard deviation of results from three independent experiments. ${ }^{* * * *} \mathrm{P}<0.0001$ vs. controls (schisandrin A- and LPS-untreated cells); ${ }^{\# \# *} \mathrm{P}<0.0001$ vs. cells cultured with $100 \mathrm{ng} / \mathrm{ml}$ LPS. (C and D) RAW 264.7 cells were pretreated with various concentrations of schisandrin A for $1 \mathrm{~h}$ followed by treatment with $100 \mathrm{ng} / \mathrm{ml} \mathrm{LPS} \mathrm{for} 24 \mathrm{~h}$. The total RNA was isolated and the mRNA expression of iNOS and COX-2 was analyzed using RT-PCR. (E and F) Total protein was isolated from RAW 264.7 cells pretreated with the indicated concentrations of schisandrin A followed by treatment with $100 \mathrm{ng} / \mathrm{ml} \mathrm{LPS}$ for $24 \mathrm{~h}$ and subjected to SDS-PAGE. Western blot analysis was performed using the indicated antibodies and an enhanced chemiluminescence detection system. The experiments were repeated three times and similar results were obtained. GAPDH and actin were used as internal controls for the RT-PCR and western blot assays, respectively. NO, nitric oxide; PGE prostaglandin $\mathrm{E}_{2}$; RT-PCR, reverse transcription-polymerase chain reaction; LPS, lipopolysaccharide; iNOS, inducible NO synthase; COX, cyclooxygenase.

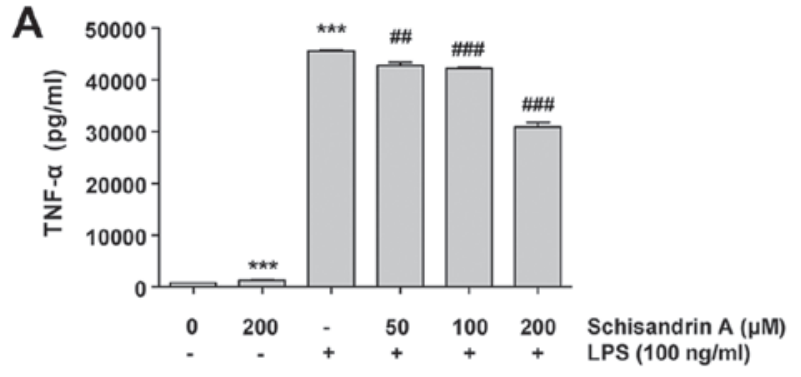

C

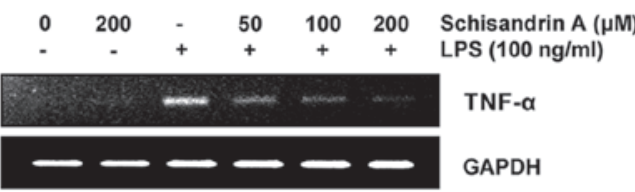

E

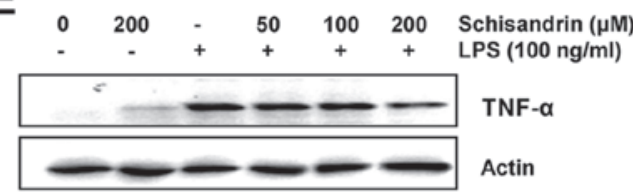

B

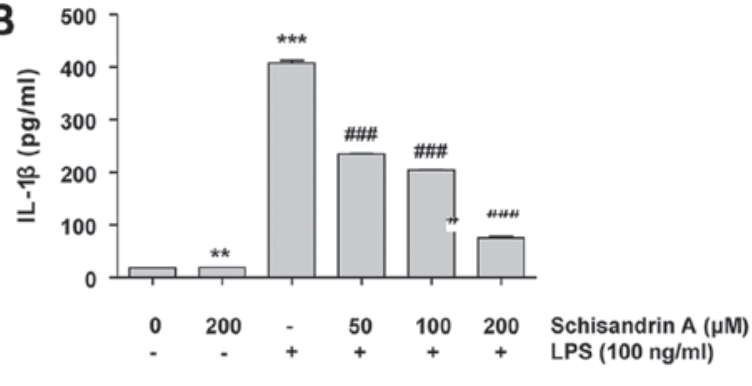

D

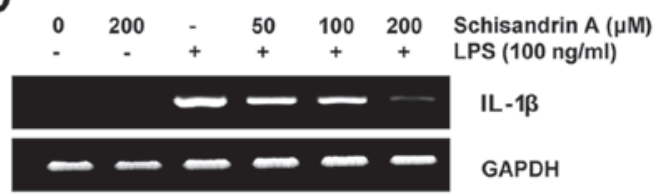

$\mathbf{F}$

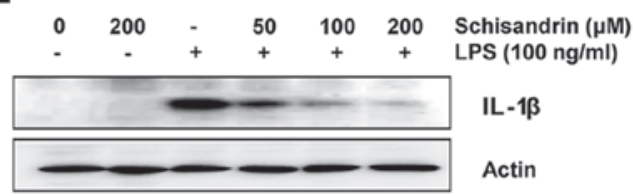

Figure 3. Inhibition of TNF- $\alpha$ and IL-1 $\beta$ production by schisandrin A in LPS-stimulated RAW 264.7 macrophages. (A and B) RAW 264.7 cells were incubated for $1 \mathrm{~h}$ with the indicated concentrations of schisandrin A prior to stimulation with LPS (100 ng/ml) for $24 \mathrm{~h}$. The amounts of (A) TNF- $\alpha$ and (B) IL-1 $\beta$ in the culture supernatants were determined using commercial ELISA kits. Values are expressed as the mean \pm standard deviation of results obtained in the three independent experiments. ${ }^{* *} \mathrm{P}<0.001$ and ${ }^{* * * *} \mathrm{P}<0.0001$ vs. controls (schisandrin $\mathrm{A}$ - and LPS-untreated cells); ${ }^{\# \#} \mathrm{P}<0.001$ and ${ }^{\# \# \#} \mathrm{P}<0.0001$ vs. cells cultured with $100 \mathrm{ng} / \mathrm{ml}$ LPS). (C and D) RAW 264.7 cells were pretreated with schisandrin A for $1 \mathrm{~h}$ followed by treatment with $100 \mathrm{ng} / \mathrm{ml} \mathrm{LPS} \mathrm{for} 24 \mathrm{~h}$, and the total RNA was isolated. The mRNA expression of TNF- $\alpha$ and IL-1 $\beta$ was analyzed using RT-PCR. (E and F) Total protein was isolated from the RAW 264.7 cells pretreated with the indicated concentrations of schisandrin A followed by treatment with $100 \mathrm{ng} / \mathrm{ml} \mathrm{LPS}$ for $24 \mathrm{~h}$ and subjected to SDS-PAGE. Western blot analyses were performed using the indicated antibodies and an enhanced chemiluminescence detection system. The experiments were repeated three times, and similar results were obtained. GAPDH and actin were used as internal controls for the RT-PCR and western blot assays, respectively. IL, interleukin; TNF, tumor necrosis factor; RT-PCR, reverse transcription-polymerase chain reaction; LPS, lipopolysaccharide. 
A

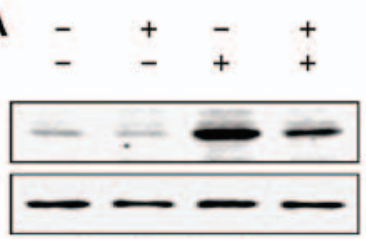

Schisandrin A $(200 \mu \mathrm{M})$ LPS (100 ng/ml)

NF-KB p65

Lamin B

Nuclear fraction

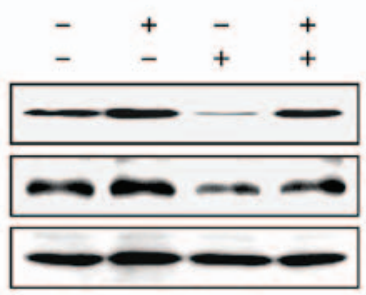

Schisandrin $\mathrm{A}(200 \mu \mathrm{M})$ LPS (100 ng/ml)

NF-kB p65

IKB- $\alpha$

Actin

Cytosolic fraction
B

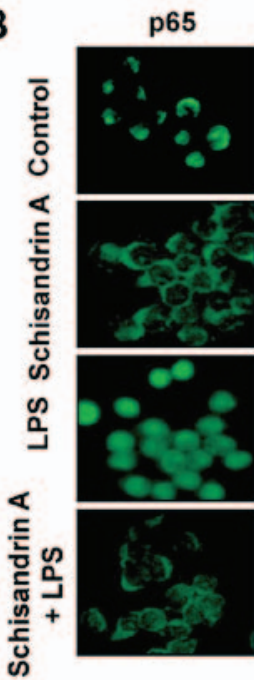

DAPI

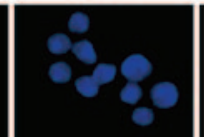

Merged

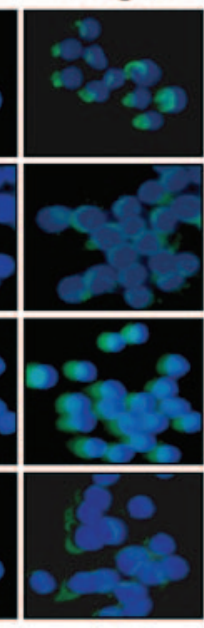

Figure 4. Effect of schisandrin A on LPS-induced nuclear translocation of NF- $\kappa$ B in RAW 264.7 macrophages. The cells were treated with $200 \mu \mathrm{M}$ schisandrin A for $1 \mathrm{~h}$ prior to treatment with $100 \mathrm{ng} / \mathrm{ml}$ LPS for $30 \mathrm{~min}$. (A) Nuclear and cytosolic proteins were subjected to $10 \%$ SDS-PAGE followed by western

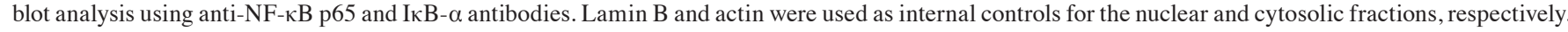
(B) The cells were pretreated with $200 \mu \mathrm{g} / \mathrm{ml}$ schisandrin A for $1 \mathrm{~h}$ prior to stimulation with $100 \mathrm{ng} / \mathrm{ml} \mathrm{LPS}$ for $30 \mathrm{~min}$. Localization of NF- $\mathrm{BB}$ p65 was visualized following immunofluorescence staining with anti-NF- $\mathrm{B}$ p65 antibody (green). The cells were also stained with DAPI for visualization of nuclei (blue). The cells were visualized using a fluorescence microscope (magnification, $\mathrm{x} 400$ ). NF, nuclear factor; IкB- $\alpha$, inhibitor of NF- $\kappa \mathrm{B}$; LPS, lipopolysaccharide.

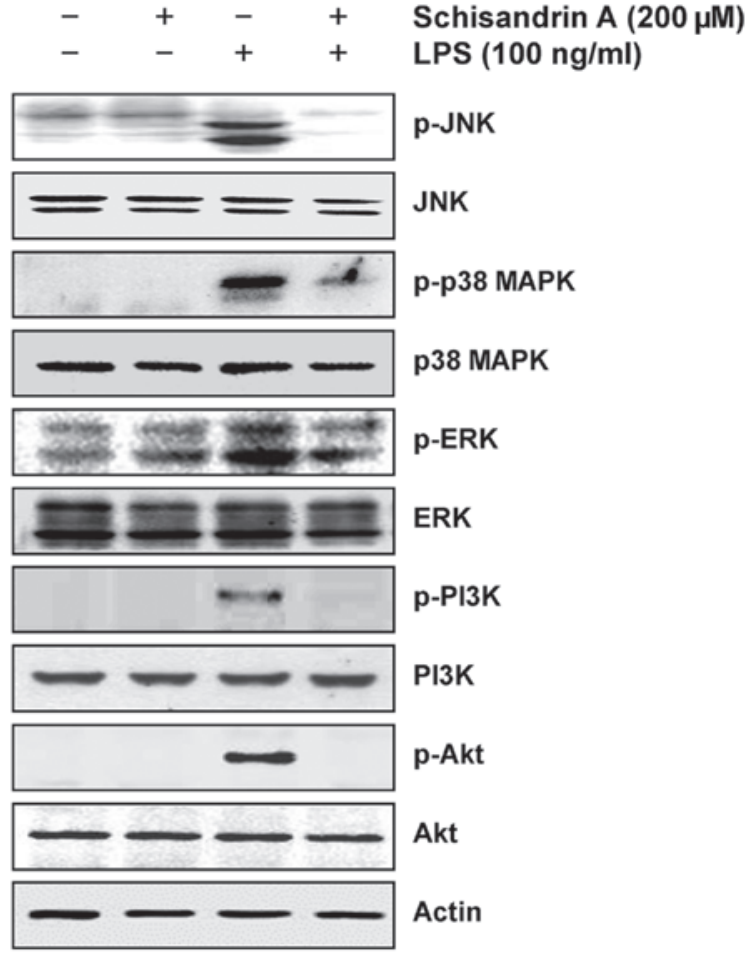

Figure 5. Effect of schisandrin A on LPS-induced activation of MAPKs and PI3K/Akt pathway components in RAW 264.7 macrophages. The cells were pretreated with $200 \mu \mathrm{M}$ schisandrin A for $1 \mathrm{~h}$ prior to exposure to LPS $(100 \mathrm{ng} / \mathrm{ml})$ for $30 \mathrm{~min}$, and total protein was isolated. The protein was subjected to SDS-PAGE followed by western blot analysis using the indicated antibodies and an enhanced chemiluminescence detection system. The experiments were repeated three times and similar results were obtained. Actin was used as an internal control. LPS, lipopolysaccharide; MAPK, mitogenactivated protein kinase; p-JNK, phosphorylated c-Jun N-terminal kinase; ERK, extracellular signal-regulated kinase; PI3K, phosphoinositide-3 kinase.

and Akt (Fig. 5); however, these effects were completely abrogated by pretreatment with schisandrin A. Thus, schisandrin A suppresses the inflammatory response by inactivating the MAPK and PI3K/Akt signaling pathways in LPS-stimulated RAW 264.7 macrophages.

Schisandrin A inhibits LPS-induced ROS production in RAW 264.7 macrophages. Previous studies have demonstrated that inflammation is partly mediated by oxidative stressors and that LPS-activated macrophages increase ROS accumulation $(4,5)$. Thus, the protective effect of schisandrin A on intracellular ROS formation in LPS-stimulated RAW 264.7 cells was investigated using the DCF-DA assay. Fig. 6 indicates that following LPS treatment, the DCF fluorescence intensity was significantly increased. Furthermore, pretreatment with schisandrin A or NAC, an antioxidant, significantly reversed the LPS-induced increases in the ROS content. These results confirmed that the anti-inflammatory effect of schisandrin A may be associated with its antioxidant activity.

Induction of $\mathrm{Nrf} 2$ and $\mathrm{HO}-1$ expression by schisandrin A in RAW 264.7 macrophages. The Nrf2/HO-1 signaling system has a vital role in intracellular antioxidant systems $(16,18)$. The present study further investigated whether Nrf2/HO-1 signaling is involved in the antioxidant effect of schisandrin A. Western blot analysis indicated that with the increase in the treatment duration and concentration of schisandrin A, the expression of Nrf2 gradually increased; simultaneously, the expression of Kelch-like ECH-associated protein 1 (Keap1), a negative regulator of $\mathrm{Nrf} 2$, decreased. In addition, schisandrin A effectively increased HO-1 expression (Fig. 7A and B), indicating that the antioxidant effect of schisandrin $\mathrm{A}$ is associated with the activation of the Nrf2/HO-1 signaling pathway. Furthermore, immunoblot analysis using the nuclear and cytosolic fractions of the RAW 264.7 cells revealed that the amount of total and phosphorylated Nrf2 protein in the nucleus was markedly increased following schisandrin A treatment (Fig. 7C and D). 

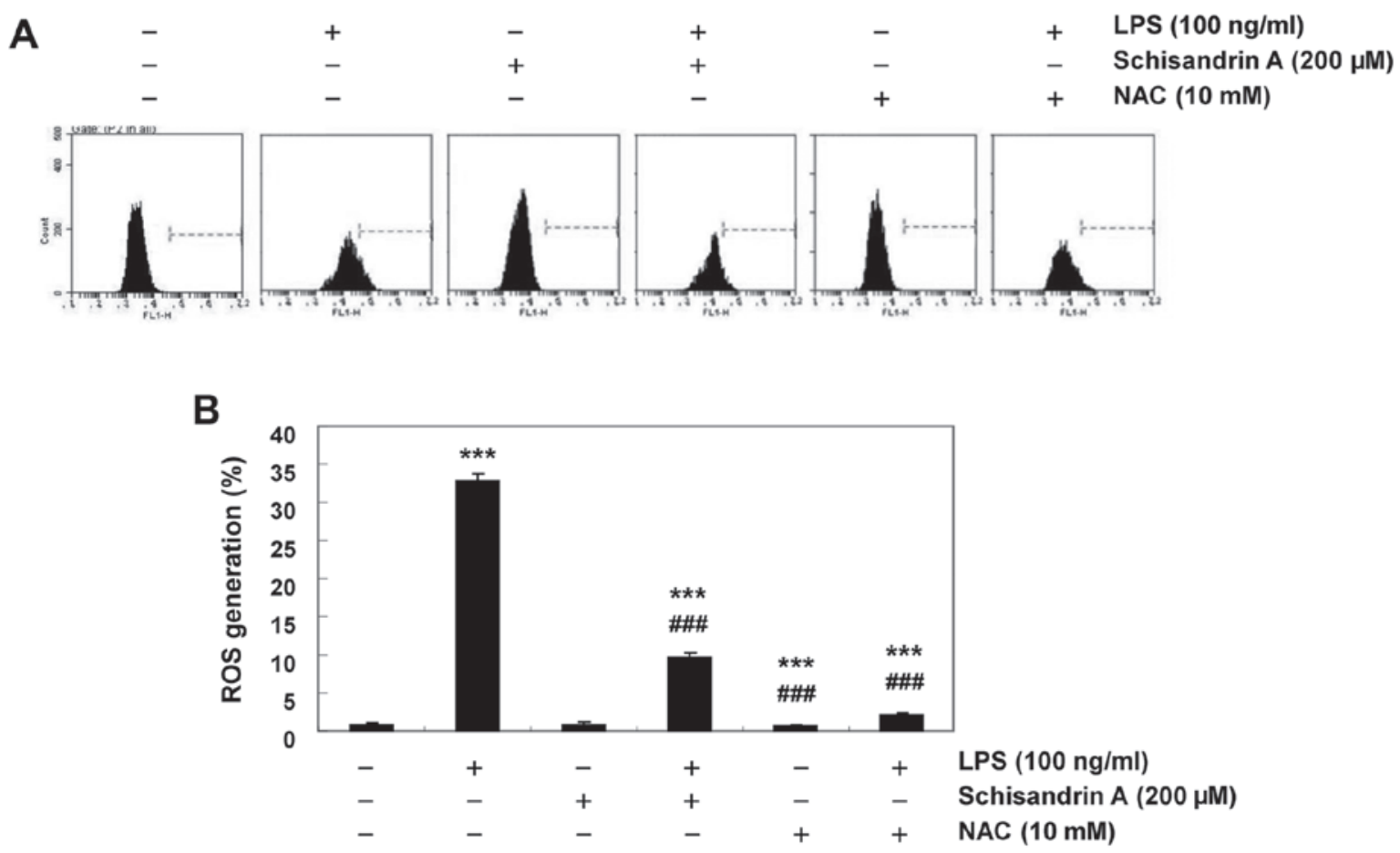

Figure 6. Effects of schisandrin A on LPS-induced ROS generation in RAW 264.7 macrophages. RAW 264.7 cells were pretreated with $200 \mu \mathrm{M}$ schisandrin A or $10 \mathrm{mM} \mathrm{NAC}$ for $1 \mathrm{~h}$, and then stimulated with or without $100 \mathrm{ng} / \mathrm{ml} \mathrm{LPS} \mathrm{for} 6 \mathrm{~h}$. The cells were incubated at $37^{\circ} \mathrm{C}$ in the dark for $20 \mathrm{~min}$ with a culture medium containing $10 \mu \mathrm{M}$ 5,6-carboxy-2'7'-dichlorofluorescin diacetate to monitor ROS production. (A) ROS generation was measured using flow cytometry. (B) Quantified levels of ROS. Values are expressed as the mean \pm standard deviation of the three independent experiments. ${ }^{* * *} \mathrm{P}<0.0001$ vs. controls (schisandrin A- and LPS-untreated cells); ${ }^{\# \# ~} \mathrm{P}<0.0001$ vs. cells cultured with $100 \mathrm{ng} / \mathrm{ml}$ LPS. NAC, N-acetyl cysteine; ROS, reactive oxygen species; LPS, lipopolysaccharide.

A

A

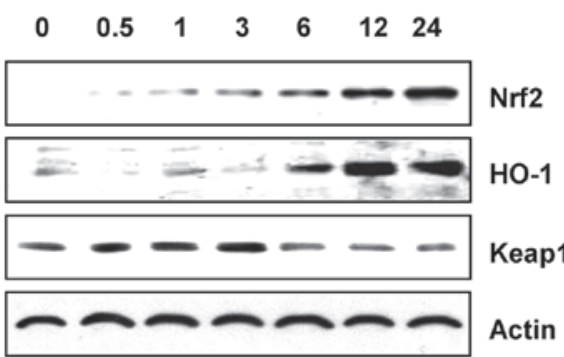

Schisandrin A $(200 \mu \mathrm{M})$

C

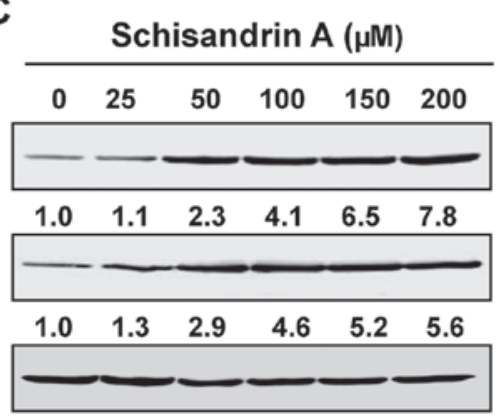

Nuclear fraction
B

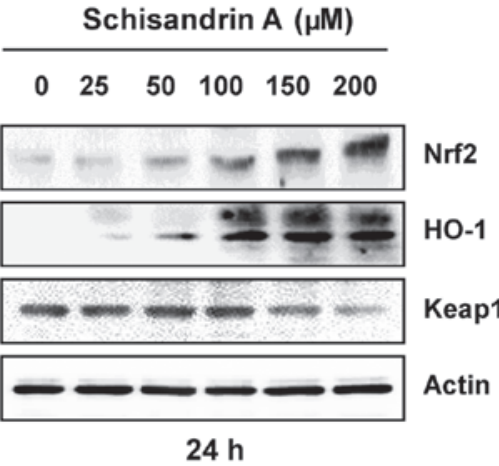

D

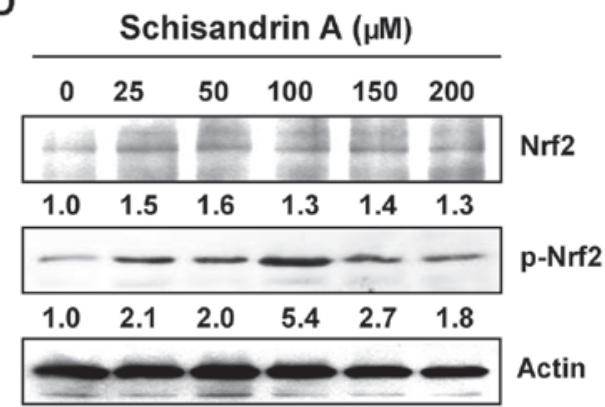

Cytosolic fraction

Figure 7. Induction of Nrf2 and HO-1 expression by schisandrin A in RAW 264.7 macrophages. The cells were incubated with $200 \mu \mathrm{M}$ schisandrin A for the indicated periods or with the indicated concentrations of schisandrin A for $24 \mathrm{~h}$. (A and B) Total cellular protein was separated by SDS-PAGE and then transferred onto membranes. The membranes were probed with the indicated antibodies for western blot analysis. (C and D) Nuclear or cytosolic proteins were probed with anti-Nrf2 and anti-p-Nrf2 antibodies. Proteins were visualized using an enhanced chemiluminescence detection system. The experiments were repeated three times, and similar results were obtained. Lamin B and actin were used as internal controls for the nuclear and cytosolic fractions, respectively. p-Nrf2, phosphorylated nuclear factor erythroid 2-related factor 2; HO-1, heme oxygenase-1; Keap1; Kelch-like ECH-associated protein 1. 


\section{Discussion}

Macrophages have a critical role in initiating inflammation and the innate and adaptive immune response. For this purpose, macrophages undergo a series of processes involving the activation and release of several specific effector proteins, including pro-inflammatory mediators and cytokines, when stimulated by LPS, a major component of the outer membrane of Gram-negative bacteria $(1,2)$. This process may be accompanied by oxidative stress, an important target for anti-inflammatory drugs. Therefore, nutraceutical agents that modulate inflammatory mediators in activated macrophages have been the focus of recent research and may prove useful in the treatment of inflammatory diseases with minimal adverse effects.

The present study demonstrated the in vitro anti-inflammatory properties of schisandrin A in LPS-stimulated RAW 264.7 cells and proposed an underlying mechanism of action. LPS derived from E. coli was used to generate the most widely used experimental model to date for assessing the capacity of drugs to inhibit the inflammatory response $(1,2)$. As in previous similar studies, it has been shown that LPS treatment increased the production of pro-inflammatory mediators, including $\mathrm{NO}$ and $\mathrm{PGE}_{2}$, in RAW 264.7 cells (3-6); however, pretreatment with schisandrin A inhibited their production in a concentrationdependent manner without affecting the cell viability. It was also revealed that LPS-induced mRNA and protein expression of iNOS as well as COX-2 was effectively inhibited by schisandrin A in a dose-dependent manner. Although appropriate NO levels influence numerous physiological conditions, excessive levels of iNOS-induced NO in macrophages is closely associated with several inflammatory diseases (6,7). In addition, $\mathrm{PGE}_{2}$ produced from arachidonic acid by the action of prostanaseforming enzyme COX-2 is mainly generated in response to various inflammatory stimuli, and COX-2 overexpression promotes inflammatory signaling cascades $(6,8)$. During the inflammatory response, activated macrophages also produce pro-inflammatory cytokines, including TNF- $\alpha$ and IL-1 $\beta$, which influence acute as well as chronic inflammation; therefore, reduction of these cytokines may delay the inflammatory response $(10,11)$. In the present study, alongside the inhibition of LPS-induced $\mathrm{NO}$ and $\mathrm{PGE}_{2}$ generation, LPS-activated TNF- $\alpha$ and IL-1 $\beta$ protein secretion and gene expression were also effectively inhibited by schisandrin A.

To further elucidate the schisandrin A-mediated antiinflammatory mechanisms, the present study examined whether schisandrin $\mathrm{A}$ affects the activation of NF- $\mathrm{KB}$, an important transcription factor involved in controlling DNA transcription and cytokine production in response to inflammation $(12,13)$. Under basal conditions, NF- $\mathrm{\kappa B}$ is present in the cytoplasm as a heterodimer with its specific inhibitor IкB- $\alpha$. IкB is rapidly phosphorylated and degraded by the ubiquitination-mediated $26 \mathrm{~S}$ proteasome when macrophages are induced by inflammatory stimuli, including LPS $(4,5,12)$. The liberated NF- $\kappa B$ then translocates to the nucleus and binds to the NF- $\mathrm{kB}$ binding site to initiate the transcription of various inflammatory genes, leading to the development and progression of inflammation $(13,14)$. Thus, blocking the translocation of NF- $\mathrm{BB}$ to the nucleus is considered an important target for agents developed to inhibit the inflammatory response. In the present study, it was observed that schisandrin A suppresses LPS-induced
I $\kappa \mathrm{B}$ degradation, thus maintaining NF- $\kappa \mathrm{B}$ in the cytoplasm and decreasing nuclear translocation to ultimately reduce the expression of the above-mentioned inflammatory genes.

It has been reported that the activation of NF- $\mathrm{KB}$ by LPS is followed by a series of events, leading to the activation of signaling pathways, including MAPKs and PI3K/Akt that are crucial for regulating inflammation and producing inflammatory factors $(13,14)$. To investigate whether the MAPK signaling pathways are involved in the schisandrin A-induced inhibition of the inflammatory response, the effects of schisandrin A on the activation of the three MAPKs (JNK, p38 MAPK and ERK) were investigated, revealing that the LPS-induced phosphorylation of all the three MAPKs was markedly suppressed by schisandrin A pretreatment. In addition, schisandrin A also reduced the LPS-induced phosphorylation PI3K and Akt, a dominant effector of PI3K signaling $(13,14)$, in RAW 264.7 cells. This implied that schisandrin A reduced LPS-induced inflammation, at least partially, by inhibiting the MAPK and $\mathrm{PI} 3 \mathrm{~K} / \mathrm{Akt}$ signaling pathways, which in turn blocked NF- $\mathrm{kB}$ inactivation.

While the production of an abnormally high amounts of ROS stimulates the recruitment of additional macrophages to the inflammation site for the release of pro-inflammatory mediators and cytokines $(1,37,38)$, LPS is known to rapidly stimulate ROS production in macrophages and induce the secretion of inflammatory mediators and cytokines $(37,39)$. The present study demonstrated that in RAW 264.7 macrophages stimulated by LPS, schisandrin A significantly attenuated ROS generation. Although the exact mechanisms of the association between the production of ROS and the activation of NF- $\mathrm{KB}, \mathrm{MAPKs}$, and PI3K/Akt requires further investigation, the present results indicate that inhibition of ROS generation is an important component of the anti-inflammatory effects of schisandrin A.

Nrf2 is a key coordinator for improving the intracellular responses to several oxidative and inflammatory insults. Furthermore, the beneficial effects of Nrf2 in various diseases have been previously reported $(16,40)$. Under normal redox conditions, Nrf2 is bound to Keap1, a representative repressor protein of Nrf2, in the cytoplasm, and is easily degraded through the ubiquitin-proteasome pathway. However, when exposed to a stressor or inducer, Nrf2 dissociates from Keap1, migrates to the nucleus, and is sequestered to the antioxidant response elements of cytoprotective and antioxidant enzymes to promote gene expression $(13,18)$. The results of the present study indicated that Nrf2 expression increased considerably with the increase in the concentration and duration of schisandrin A treatment. In addition, a concomitant decrease in Keapl accompanied by the translocation of Nrf2 into the nuclei was observed. Furthermore, the expression of HO-1, a representative target gene of Nrf2, was also significantly elevated by schisandrin A treatment. HO-1 catalyzes the decomposition of heme to iron, carbon monoxide and biliverdin, which in turn is converted to bilirubin by biliverdin reductase (40-42). The products of this enzymatic reaction have an important biological role in antioxidant and cytoprotective processes through eliminating ROS to suppress cell damage and death $(17,42,43)$. Although further study assessing the association between the inhibition of ROS production and the activation of Nrf2/HO-1 signaling is warranted, the present results suggest that schisandrin A-mediated induction of 
Nrf2 and HO-1 may contribute to the inhibition of the inflammatory response to LPS by decreasing oxidative stress in RAW 264.7 macrophages.

The fruit of Schizandra chinensis contains a variety of lignan compounds, including schisandrin A, and has long been used in the treatment of gastrointestinal disorders, respiratory insufficiency, cardiovascular disease, physical fatigue and weakness, excessive sweating and insomnia in East-Asia $(22,44)$. In Russian traditional medicine, it has also been used as a tonic and a natural medicine with restorative and anti-aging effects, as well as the ability to improve vitality and mental wellbeing (19). Although clinical studies on the anti-inflammatory effects of the fruit of Schizandra chinensis are limited, it has been reported to have beneficial effects on necrotizing inflammatory variables in patients with chronic hepatitis C (45). Therefore, the value of studies evaluating the various pharmacological effects of lignan compounds derived from the fruit of Schizandra chinensis, including the present study, are important, and the present results suggested that schisandrin A may be beneficial in patients with persistent and systemic inflammation.

In conclusion, the results of the present study indicated that schisandrin A exerts anti-inflammatory effects by inhibiting the ROS production and reducing the activity of the MAPK and PI3K/Akt pathways, resulting in the inhibition of $\mathrm{NF}-\kappa \mathrm{B}$, particularly in association with the activation of $\mathrm{Nrf} 2 / \mathrm{HO}-1$ signaling. This, in turn, inhibited the transcriptional activity of the target genes of $\mathrm{NF}-\kappa \mathrm{B}$, including inflammatory mediators and cytokines, in a model of LPS-activated RAW 264.7 macrophages. Although further investigation of the precise underlying mechanisms is required, it is concluded that schisandrin A may be a natural bioactive compound that exerts anti-inflammatory effects by modulating multiple signaling pathways and may be a useful agent for treating inflammation-mediated disease states.

\section{Acknowledgements}

This study was supported by the High Value-added Food Technology Development Program (grant no. 314043-3), the Ministry of Agriculture, Food and Rural Affairs, the International Science and Business Belt Program through the Ministry of Science, ICT and Future Planning (grant no. 2016K000297) and Blue-Bio Industry Regional Innovation Center (RIC; grant no. RIC08-06-07) at Dongeui University as an RIC program under the Ministry of Trade, Industry and Energy and Busan city.

\section{References}

1. Cuschieri J and Maier RV: Oxidative stress, lipid rafts, and macrophage reprogramming. Antioxid Redox Signal 9: $1485-1497,2007$.

2. Lucas K and Maes M: Role of the Toll like receptor (TLR) radical cycle in chronic inflammation: Possible treatments targeting the TLR4 pathway. Mol Neurobiol 48: 190-204, 2013.

3. Leiro J, Alvarez E, Arranz JA, Laguna R, Uriarte E and Orallo F: Effects of cis-resveratrol on inflammatory murine macrophages: Antioxidant activity and down-regulation of inflammatory genes. J Leukoc Biol 75: 1156-1165, 2004.

4. Su YW, Chiou WF, Chao SH, Lee MH, Chen CC and Tsai YC: Ligustilide prevents LPS-induced iNOS expression in RAW 264.7 macrophages by preventing ROS production and down-regulating the MAPK, NF- $\mathrm{BB}$ and AP-1 signaling pathways. Int Immunopharmacol 11: 1166-1172, 2011.
5. Hong SH, Jeong HK, Han MH, Park C and Choi YH: Esculetin suppresses lipopolysaccharide-induced inflammatory mediators and cytokines by inhibiting nuclear factor- $\mathrm{kB}$ translocation in RAW 264.7 macrophages. Mol Med Rep 10: 3241-3246, 2014

6. Murakami A and Ohigashi H: Targeting NOX, INOS and COX-2 in inflammatory cells: Chemoprevention using food phytochemicals. Int J Cancer 121: 2357-2363, 2007.

7. Yang GY, Taboada S and Liao J: Induced nitric oxide synthase as a major player in the oncogenic transformation of inflamed tissue. Methods Mol Biol 512: 119-156, 2009.

8. Norberg JK, Sells E, Chang HH, Alla SR, Zhang S and Meuillet EJ: Targeting inflammation: Multiple innovative ways to reduce prostaglandin $\mathrm{E}_{2}$. Pharm Pat Anal 2: 265-288, 2013.

9. Kim J, Kim J and Bae JS: ROS homeostasis and metabolism: A critical liaison for cancer therapy. Exp Mol Med 48: e269, 2016.

10. Klapproth JM and Sasaki M: Bacterial induction of proinflammatory cytokines in inflammatory bowel disease. Inflamm Bowel Dis 16: 2173-2179, 2010.

11. Striz I, Brabcova E, Kolesar L and Sekerkova A: Cytokine networking of innate immunity cells: A potential target of therapy. Clin Sci (Lond) 126: 593-612, 2014.

12. Endale M, Park SC, Kim S, Kim SH, Yang Y, Cho JY and Rhee MH: Quercetin disrupts tyrosine-phosphorylated phosphatidylinositol 3-kinase and myeloid differentiation factor-88 association, and inhibits MAPK/AP-1 and IKK/NF- $\mathrm{kB}$-induced inflammatory mediators production in RAW 264.7 cells. Immunobiology 218: 1452-1467, 2013.

13. Huang BP, Lin CH, Chen HM, Lin JT, Cheng YF and Kao SH: AMPK activation inhibits expression of proinflammatory mediators through downregulation of PI3K/p38 MAPK and NF- $\mathrm{\kappa B}$ signaling in murine macrophages. DNA Cell Biol 34: 133-141, 2015.

14. Jung JS, Choi MJ, Lee YY, Moon BI, Park JS and Kim HS: Suppression of lipopolysaccharide-induced neuroinflammation by morin via MAPK, PI3K/Akt, and PKA/HO-1 signaling pathway modulation. J Agric Food Chem 65: 373-382, 2017.

15. Nakajima $S$ and Kitamura M: Bidirectional regulation of NF- $\kappa B$ by reactive oxygen species: A role of unfolded protein response. Free Radic Biol Med 65: 162-174, 2013.

16. Huang Y, Li W, Su ZY and Kong AN: The complexity of the Nrf2 pathway: Beyond the antioxidant response. J Nutr Biochem 26: 1401-1413, 2015.

17. Loboda A, Damulewicz M, Pyza E, Jozkowicz A and Dulak J: Role of Nrf2/HO-1 system in development, oxidative stress response and diseases: An evolutionarily conserved mechanism. Cell Mol Life Sci 73: 3221-3247, 2016.

18. Kang KA and Hyun JW: Oxidative stress, Nrf2, and epigenetic modification contribute to anticancer drug resistance. Toxicol Res 33: 1-5, 2017.

19. Panossian A and Wikman G: Pharmacology of Schisandra chinensis Bail.: An overview of Russian research and uses in medicine. J Ethnopharmacol 118: 183-212, 2008.

20. Liang CQ, Luo RH, Yan JM, Li Y, Li XN, Shi YM, Shang SZ, Gao ZH, Yang LM, Zheng YT, et al: Structure and bioactivity of triterpenoids from the stems of Schisandra sphenanthera. Arch Pharm Res 37: 168-174, 2014.

21. Xiao WL, Huang SX, Wang RR, Zhong JL, Gao XM, He F, Pu JX, Lu Y, Zheng YT, Zheng QT, et al: Nortriterpenoids and lignans from Schisandra sphenanthera. Phytochemistry 69: 2862-2866, 2008.

22. Chun JN, Cho M, So I and Jeon JH: The protective effects of Schisandra chinensis fruit extract and its lignans against cardiovascular disease: A review of the molecular mechanisms. Fitoterapia 97: 224-233, 2014.

23. Huyke C, Engel K, Simon-Haarhaus B, Quirin KW and Schempp CM: Composition and biological activity of different extracts from Schisandra sphenanthera and Schisandra chinensis. Planta Med 73: 1116-1126, 2007.

24. Kim SR, Lee MK, Koo KA, Kim SH, Sung SH, Lee NG, Markelonis GJ, Oh TH, Yang JH and Kim YC: Dibenzocyclooctadiene lignans from Schisandra chinensis protect primary cultures of rat cortical cells from glutamateinduced toxicity. J Neurosci Res 76: 397-405, 2004.

25. Wang CP, Li GC, Shi YW, Zhang XC, Li JL, Wang ZW, Ding F and Liang XM: Neuroprotective effect of schizandrin A on oxygen and glucose deprivation/reperfusion-induced cell injury in primary culture of rat cortical neurons. J Physiol Biochem 70: 735-747, 2014.

26. EQ, Tang M,Zhang X, Shi Y, Wang D, Gu Y, Li S, Liang X, Wang Z and Wang C: Protection of seven dibenzocyclooctadiene lignans from Schisandra chinensis against serum and glucose deprivation injury in SH-SY5Y cells. Cell Biol Int 39: 1418-1424, 2015. 
27. Song F, Zeng K, Liao L, Yu Q, Tu P and Wang X: Schizandrin A inhibits microglia-mediated neuroninflammation through inhibiting TRAF6-NF- $\kappa$ B and Jak2-Stat3 signaling pathways. PLoS One 11: e0149991, 2016.

28. Leong PK, Wong HS, Chen J, Chan WM, Leung HY and Ko KM: Differential action between schisandrin A and schisandrin B in eliciting an anti-inflammatory action: The depletion of reduced glutathione and the induction of an antioxidant response. PLoS One 11: e0155879, 2016.

29. Checker R, Patwardhan RS, Sharma D, Menon J, Thoh M, Bhilwade HN, Konishi T and Sandur SK: Schisandrin B exhibits anti-inflammatory activity through modulation of the redoxsensitive transcription factors $\mathrm{Nrf} 2$ and $\mathrm{NF}-\kappa \mathrm{B}$. Free Radic Biol Med 53: 1421-1430, 2012

30. Park SY, Park SJ, Park TG, Rajasekar S, Lee SJ and Choi YW: Schizandrin $\mathrm{C}$ exerts anti-neuroinflammatory effects by upregulating phase II detoxifying/antioxidant enzymes in microglia. Int Immunopharmacol 17: 415-426, 2013.

31. Xie Y, Hao H, Wang H, Guo C, Kang A and Wang G: Reversing effects of lignans on CCl4-induced hepatic CYP450 down regulation by attenuating oxidative stress. J Ethnopharmacol 155: 213-221, 2014.

32. Ba Q, Cui C, Wen L, Feng S, Zhou J and Yang K: Schisandrin B shows neuroprotective effect in 6-OHDA-induced Parkinson's disease via inhibiting the negative modulation of miR-34a on Nrf2 pathway. Biomed Pharmacother 75: 165-172, 2015.

33. Dong Q, Hou H, Wu J and Chen Y: The Nrf2-ARE pathway is associated with Schisandrin b attenuating benzo(a)pyreneInduced HTR cells damages in vitro. Environ Toxicol 31: 1439-1449, 2016

34. Gao C, Chen H, Niu C, Hu J and Cao B: Protective effect of Schizandrin B against damage of UVB irradiated skin cells depend on inhibition of inflammatory pathways. Bioengineered 8 : 36-44, 2017.

35. Lee IC, Lee SM, Ko JW, Park SH, Shin IS, Moon C, Kim SH and Kim JC: Role of mitogen-activated protein kinases and nuclear factor-kappa B in 1,3-dichloro-2-propanol-induced hepatic injury. Lab Anim Res 32: 24-33, 2016.

36. Kim HK: Adenophora remotiflora protects human skin keratinocytes against UVB-induced photo-damage by regulating antioxidative activity and MMP-1 expression. Nutr Res Pract 10: 371-376, 2016.
37. Hernández-Ledesma B,Hsieh CC and de Lumen BO: Antioxidant and anti-inflammatory properties of cancer preventive peptide lunasin in RAW 264.7 macrophages. Biochem Biophys Res Commun 390: 803-808, 2009.

38. Mittal M, Siddiqui MR, Tran K, Reddy SP and Malik AB: Reactive oxygen species in inflammation and tissue injury. Antioxid Redox Signal 20: 1126-1167, 2014.

39. Kasahara E, Sekiyama A, Hori M, Hara K, Takahashi N, Konishi M, Sato EF, Matsumoto S, Okamura H and Inoue M: Mitochondrial density contributes to the immune response of macrophages to lipopolysaccharide via the MAPK pathway. FEBS Lett 585: 2263-2268, 2011.

40. Lee DH, Park JS, Lee YS, Sung SH, Lee YH and Bae SH: The hypertension drug, verapamil, activates Nrf2 by promoting p62-dependent autophagic Keap1 degradation and prevents acetaminophen-induced cytotoxicity. BMB Rep 50: 91-96, 2017.

41. Pittalà V, Salerno L, Romeo G, Modica MN and Siracusa MA: A focus on heme oxygenase-1 (HO-1) inhibitors. Curr Med Chem 20: 3711-3732, 2013.

42. Ryter SW and Choi AM: Targeting heme oxygenase-1 and carbon monoxide for therapeutic modulation of inflammation. Transl Res 167: 7-34, 2016.

43. Motterlini R and Foresti R: Heme oxygenase-1 as a target for drug discovery. Antioxid Redox Signal 20: 1810-1826, 2014.

44. Szopa A, Ekiert R and Ekiert H: Current knowledge of Schisandra chinensis (Turcz.) Baill. (Chinese magnolia vine) as a medicinal plant species: A review on the bioactive components, pharmacological properties, analytical and biotechnological studies. Phytochem Rev 16: 195-218, 2017.

45. Melhem A, Stern M, Shibolet O, Israeli E, Ackerman Z, Pappo O, Hemed N, Rowe M, Ohana H, Zabrecky G, et al: Treatment of chronic hepatitis $\mathrm{C}$ virus infection via antioxidants: Results of a phase I clinical trial. J Clin Gastroenterol 39: 737-742, 2005.

This work is licensed under a Creative Commons Attribution-NonCommercial-NoDerivatives 4.0 International (CC BY-NC-ND 4.0) License. 